Article

\title{
Explosive Strength Capacity in the Lower Limbs of Primary Education School Children According to Environment
}

\author{
Amador Jesús Lara Sánchez ${ }^{1, *(1)}$, Francisco José López Gallego ${ }^{1}$ (1) , José Antonio Pérez Turpin ${ }^{2}$ \\ and Javier Cachón Zagalaz ${ }^{1}$ \\ 1 Faculty of Humanities and Education Sciences, University of Jaén, 23071 Jaén, Spain; \\ franloga92@hotmail.com (F.J.L.G.); jcachon@ujaen.es (J.C.Z.) \\ 2 Faculty of Education, Department of General and Especially Didactic, University of Alicante, 03080 Alicante, \\ Spain; jose.perez@ua.es \\ * Correspondence: alara@ujaen.es; Tel.: +34-636-834-303
}

Received: 16 February 2018; Accepted: 10 March 2018; Published: 14 March 2018

\begin{abstract}
The objective of this study was to compare the corporal composition and the explosive strength capacity of lower limbs in primary school students from two different schools in the locality of Martos (Jaén). One of these schools was located in a marginalized neighbourhood where families of low socioeconomic status lived and the other was near the town centre with families of medium to high socioeconomic status. The aim was to evaluate these variables at two different moments in time, i.e., at the beginning and at the end of the school year, to see if the obtained results remained the same. A total of 147 primary school students (6-12 years old) participated in the study, divided into 4 subgroups, according to sex and school. Body composition and explosive strength capacity of the lower limbs were evaluated using the vertical jump test. For independent samples, $T$ tests were performed to obtain the existing differences through the SPSS v 19.0 programme. It was found that according to the first measurement at the beginning of the year, participants from a medium-high socioeconomic background obtained better results, while the second measurement showed that results equalized and even reversed. This could have been due to the level of performed physical activity.
\end{abstract}

Keywords: primary school; physical condition; force platform

\section{Introduction}

Sustainable development is understood as a system that human beings are part of, in a process that harmonizes social equity, among other variables, at all levels within a political context [1]. Therefore, it is interesting to compare some of the main variables determining physical/sports skills in relation to background: this way we can observe whether or not some authentic social equity exists in this respect.

Among the different variables used to evaluate physical/sports skills, physical condition is particularly interesting to examine because it acts as a health marker, as indicated in a large number of studies [2-4]. Several authors have studied the relationship between physical condition and other factors such as the environment [5], gender [6-8] and socioeconomic status $[9,10]$.

However, regarding socioeconomic status, no complete agreement has been reached as to the direction of the relationship. One study points out that in the case of men, the socioeconomic level is inversely related to physical condition, while in the case of women, this relationship is positive [9]. Other authors point out that this relationship is positive in both cases [10,11].

Also worthy of note is that strength, among the capacities making up physical condition, is of special interest: it underlies other physical abilities [12], and developing strength has beneficial effects 
on health [13,14]. The tests and materials most commonly used to evaluate strength and that stand out in the literature are: the Abalakob jump test (ABK); jumps with countermovement (CMJ) and without countermovement (SJ) and force platforms [15-17]. The objective of this study was to compare the body composition and explosive strength capacity of lower limb extension in primary school students from two educational centres in the town of Martos (Jaén, Spain) in order to verifyif there is a true social equality in this aspect. This study evaluates these variables at two different times-at the beginning and at the end of the school year-and to observe whether the results remained the same. As sex can affect results, the sample was subdivided according to the sex variable.

\section{Materials and Methods}

\subsection{Sample}

A total of 147 primary school students participated in this study, divided into 4 subgroups, depending on the sex and centre. One school was located in a marginalized area with families of low socioeconomic status and another in a central area with families of medium to high socioeconomic status. In this research, medium and high socioeconomic status were evaluated together because they had few participants from a high socio-economic status. The characteristics of age, body mass, body height and body mass index (BMI) of both the total sample and that of each of the subgroups separately are shown in Table 1.

Table 1. Characteristics of the sample (Low-L = Low socioeconomic level; High-L = High socioeconomic level).

\begin{tabular}{|c|c|c|c|c|c|c|}
\hline & & $\mathbf{N}$ & Age (Years) & Body Mass (kg) & Body Height (cm) & BMI $\left(\mathrm{kg} / \mathrm{m}^{2}\right)$ \\
\hline \multirow[t]{2}{*}{ Boys } & Low-L & 29 & $8.38 \pm 1.61$ & $33.79 \pm 9.28$ & $132.38 \pm 10.92$ & $18.93 \pm 3.57$ \\
\hline & High-L & 44 & $8.95 \pm 1.38$ & $37.68 \pm 10.23$ & $139.14 \pm 10.49$ & $19.17 \pm 3.29$ \\
\hline \multirow[t]{2}{*}{ Girls } & Low-L & 30 & $8.03 \pm 1.61$ & $31.04 \pm 10.03$ & $129.03 \pm 10.92$ & $18.17 \pm 3.57$ \\
\hline & High-L & 44 & $8.45 \pm 1.23$ & $36.03 \pm 11.31$ & $134.86 \pm 10.36$ & $19.48 \pm 4.28$ \\
\hline
\end{tabular}

This study respects all the rules of the Ethical committee, and we obtained the parental permission to work with children. In this study we worked with the total of all students from both educative centres.

Significantly, the school with a low socioeconomic level also had a percentage of schooled immigrant students well above average, and this could affect the interpretation of the results of this study. According to the data and figures of the 2016/17 school year provided by the Ministry of Education, Culture and Sport [18] the percentage of immigrant students per school centre within the Autonomous Community of Andalusia was 5\%, whereas it reached, in this centre, a total of $36.3 \%$.

\subsection{Process}

Body composition and explosive force capacity of the lower limbs were evaluated by vertical jump. Measurements were taken during the Physical Education class. The tests took place within the school's own sports facilities. During the tests, a series of measurements were taken with the purpose of minimizing all possible sources of error when performing the tests. The process was standardized, so that: (a) all the subjects participating in the study had the same number of attempts; (b) the tests were performed within the same facility; (c) the examiners performed a single test, so inter-observer variability was ruled out as a source of error; (d) the examiners knew the test. The first measure was taken at the beginning of the school year and the second at the end of the school year.

\subsubsection{Evaluation of Body Composition}

The anthropometric assessment was determined by measuring body mass and body height in a classroom enabled for this purpose. To determine height, the subjects were measured barefoot in a 
standing position, placing their heels, buttocks and back against a wall. A SECA (SECA Ltd., Hamburg, Germany) model height rod was used.

Body composition and BMI were evaluated through bioelectrical impedance using the INBODY 230 (Microkaya, Bilbao, Spain). A room was set at an ambient temperature of $20 \pm 2{ }^{\circ} \mathrm{C}$ for measurements. Subjects were placed on the apparatus with their heels on the footprint and their hands on the electrodes in pronosupination and an opening of arms at $45^{\circ}$ of abduction, remaining in that position for about $60 \mathrm{~s}$. Once there, an expert evaluator proceeded to assess the subject using the Lookin'Body software.

\subsubsection{Vertical Jump Test}

To measure the jump variables, a Quattro Jump force platform (Kistler, Winterthur, Switzerland) was used, connected to a laptop that collected the force records. After undergoing a few sessions to become familiar with the procedure, the subjects performed the ABK and CMJ jump tests. Before registering the tests, all the subjects performed a standardized warm-up directed by the researcher, consisting of $7 \mathrm{~min}$ of running at moderate speed, followed by $5 \mathrm{~min}$ of stretching and two series of jumps, one of sub-maximums and another of maximums. After this warm-up, the subjects performed the CMJ, with their hands on their hips, leaving the angle of flexion of the knees free. They also did the $A B K$, using their arms and leaving the angle of knee flexion free. All the subjects performed a minimum of 3 valid and maximum repetitions at each test. The ones with the highest flight height were analysed. Rest time between repetitions was $1 \mathrm{~min}$, and $1.5 \mathrm{~min}$ between jump types.

\subsection{Statistic Analysis}

For statistical data analysis, the SPSS (v.19.0, statistics for Windows, Armonk, NY, USA), was used. Descriptive statistics tests were carried out, including mean and standard deviations, both total and stratified according to sex. $T$-tests were performed for independent samples in order to obtain existing differences. In the differential tests, the statistical criterion of significance of $p<0.05$ was used.

In order to check whether significant changes had taken place between the first measurement and the second one, a $t$-test was performed for related samples, using the same statistical criterion of significance.

\section{Results}

Table 2 shows the values of body composition variables analysed in this study during the first measurement (at the beginning of the school year). Participants from the educational centre located in a medium-high socioeconomic environment had a greater body mass, body height, body mass index (BMI) and muscle percentage in the case of boys as well as girls. In addition, boys from a medium-high socioeconomic background had a lower percentage of fat, while the opposite was true for girls. However, it should be noted that none of these differences were significant, except for height in both cases, with a value of $p<0.05$.

Table 2. Results of the anthropometric assessment during the first measurement (beginning of the school year). (Low-L = Low socioeconomic level, High-L = High socioeconomic status, Dif = Differences, $\mathrm{BMI}=$ Body mass index,$\%$ Fat $=$ percentage of fat, $\%$ muscle $=$ percentage of muscle, ${ }^{*}=p<0.05$; ns = not significant).

\begin{tabular}{lccccccc}
\hline & & N & Body Mass $(\mathbf{k g})$ & Body Height $\mathbf{( c m})$ & BMI $\mathbf{( k g / \mathbf { m } ^ { 2 }}$ ) & \% Fat & \% Muscle \\
\hline Boys & Low-L & 29 & $33.79 \pm 9.28$ & $132.38 \pm 10.92$ & $18.93 \pm 3.57$ & $26.71 \pm 11.21$ & $36.99 \pm 6.61$ \\
& High-L & 44 & $37.68 \pm 10.23$ & $139.14 \pm 10.49$ & $19.17 \pm 3.29$ & $26.04 \pm 9.77$ & $38.22 \pm 4.52$ \\
& Significant Dif. & & ns & $*$ & ns & ns & ns \\
\hline \multirow{2}{*}{ Girls } & Low-L & 30 & $31.04 \pm 10.03$ & $129.03 \pm 10.92$ & $18.17 \pm 3.57$ & $26.82 \pm 11.21$ & $36.06 \pm 6.61$ \\
& High-L & 44 & $36.03 \pm 11.31$ & $134.86 \pm 10.36$ & $19.48 \pm 4.28$ & $28.78 \pm 11.03$ & $36.15 \pm 5.62$ \\
& Significant Dif. & & ns & $*$ & ns & ns & ns \\
\hline
\end{tabular}


Table 3 shows the values recorded in the jump variables CMJ and $A B K$ at the first measurement (start of school year). Boys from medium-high socio-economic backgrounds obtained higher values in all the variables. This difference was significant in all cases with a value of at least $p<0.05$. Furthermore, girls from medium-high socioeconomic backgrounds obtained better values in the peak power and height variables for both jumps, while those from a low socioeconomic level obtained better results in the strength peaks for both jumps. However, in the case of the latter, the only significant differences $(p<0.05)$ to be recorded were those of the height of both jumps.

Table 3. Results of the jump variables jumps with countermovement (CMJ) and Abalakob jump test $(\mathrm{ABK}$ ), at the first measurement (beginning of school year). (Low-L = Low socioeconomic level, High- $\mathrm{L}=$ High socioeconomic level, Dif = Differences, $\mathrm{PP}=$ power peak, $\mathrm{PF}=$ force peak, $\mathrm{H}=$ height, ${ }^{*}=p<0.05,{ }^{* *}<p<0.005 ;{ }^{* * *}=p<0.001 ;$ ns = not significant).

\begin{tabular}{|c|c|c|c|c|c|c|c|c|}
\hline & & $\mathbf{N}$ & PP_CMJ (W/Kg) & PF_CMJ (BW) & H_CMJ (cm) & PP_ABK (W/Kg) & PF_ABK (BW) & H_ABK $(\mathrm{cm})$ \\
\hline \multirow[t]{3}{*}{ Boys } & Low-L & 29 & $27.45 \pm 6.58$ & $2.2 \pm 0.49$ & $21.63 \pm 3.97$ & $29.9 \pm 6.75$ & $2.19 \pm 0.46$ & $26.75 \pm 4.41$ \\
\hline & High-L & 44 & $34.79 \pm 5.64$ & $2.59 \pm 0.46$ & $24.39 \pm 4.33$ & $38.09 \pm 6.24$ & $2.45 \pm 0.33$ & $30.14 \pm 6$ \\
\hline & Significant Dif. & & $* * *$ & $* *$ & $*$ & $* * *$ & * & * \\
\hline \multirow[t]{3}{*}{ Girls } & Low-L & 30 & $28.55 \pm 6.97$ & $2.55 \pm 0.65$ & $20.11 \pm 2.95$ & $30.54 \pm 7.6$ & $2.49 \pm 0.63$ & $24.88 \pm 3.24$ \\
\hline & High-L & 44 & $30.39 \pm 6.54$ & $2.42 \pm 0.49$ & $22.88 \pm 4.64$ & $33.42 \pm 7.12$ & $2.33 \pm 0.50$ & $28.04 \pm 5.8$ \\
\hline & Significant Dif. & & ns & ns & $*$ & ns & ns & $*$ \\
\hline
\end{tabular}

Table 4 shows the values of body composition variables obtained at the second measurement (end of school year). Differences between both groups were maintained for height in the case of boys, while for girls, the difference in this variable disappeared while it appeared for body mass, with a value of $p<0.05$.

Table 4. Results of the anthropometric assessment in the second measurement (end of school year). (Low-L = Low socioeconomic level, High-L = High socioeconomic status, Dif = Differences, $\mathrm{BMI}=$ Body mass index, $\%$ Fat $=$ percentage of fat, $\%$ muscle $=$ percentage of muscle, ${ }^{*}=p<0.05$; ns = not significant).

\begin{tabular}{cccccccc}
\hline & & N & Body Mass $\mathbf{( k g})$ & Body Height $(\mathbf{c m})$ & BMI $\mathbf{( k g / \mathbf { m } ^ { 2 } )}$ & \% Fat & \% Muscle \\
\hline \multirow{2}{*}{ Boys } & Low-L & 29 & $38.34 \pm 10.12$ & $139.03 \pm 10.81$ & $19.70 \pm 3.56$ & $28.28 \pm 10.75$ & $36.71 \pm 5.55$ \\
& High-L & 44 & $42.11 \pm 11.88$ & $144.77 \pm 10.58$ & $19.87 \pm 3.78$ & $26.71 \pm 9.93$ & $38.2 \pm 5.93$ \\
& Significant Dif.s & & $\mathrm{ns}$ & & $\mathrm{ns}$ & $\mathrm{ns}$ & $\mathrm{ns}$ \\
\hline \multirow{2}{*}{ Girls } & Low-L & 30 & $35.32 \pm 11.90$ & $136.3 \pm 10.77$ & $18.67 \pm 3.66$ & $26.33 \pm 10.18$ & $37.36 \pm 5.58$ \\
& High-L & 44 & $41.02 \pm 12.07$ & $140.8 \pm 10.05$ & $20.44 \pm 4.10$ & $30.41 \pm 10.24$ & $35.78 \pm 5.20$ \\
& Significant Dif.s & & $*$ & $\mathrm{~ns}$ & $\mathrm{~ns}$ & $\mathrm{~ns}$ & $\mathrm{~ns}$ \\
\hline
\end{tabular}

Table 5 shows the values recorded for the CMJ and ABK jump variables at the second measurement (end of school year). In the case of boys, practically all significant differences found at the first measurement disappeared, except for PF of the CMJ jump and for PP of the ABK jump. Boys from low socio-economic backgrounds were found to improve more for all the variables. However, boys from medium-high socioeconomic backgrounds still had the best values in all variables, except for strength peaks. However, as was pointed out, these differences went from being significant to ceasing to be significant.

For girls, the differences remained similar, being significant for peaks of force of both jumps and for height in the ABK jump. 
Table 5. Results of the jump variables CMJ and ABK at the second measurement (end of the school year). (Low-L = Low socioeconomic level; High-L = High socioeconomic level); Dif. = Differences; $\mathrm{PP}=$ peak power; $\mathrm{PF}=$ peak force; $\mathrm{H}=$ height; $^{*}=p<0.05 ;{ }^{* *}=p<0.005$ ).

\begin{tabular}{|c|c|c|c|c|c|c|c|c|}
\hline & & $\mathbf{N}$ & $\begin{array}{c}\text { PP_CMJ } \\
\text { (W/Kg) }\end{array}$ & PF_CMJ (BW) & H_CMJ (cm) & $\begin{array}{c}\text { PP_ABK } \\
\text { (W/Kg) }\end{array}$ & $\begin{array}{c}\text { PF_ABK } \\
\text { (BW) }\end{array}$ & $\begin{array}{c}\text { H_ABK } \\
(\mathrm{cm})\end{array}$ \\
\hline \multirow[t]{3}{*}{ Boys } & Low-L & 29 & $33.94 \pm 7.16$ & $2.71 \pm 0.48$ & $26.07 \pm 7.73$ & $37.04 \pm 7.68$ & $2.54 \pm 0.41$ & $32.65 \pm 9.56$ \\
\hline & High-L & 44 & $36.34 \pm 5.55$ & $2.47 \pm 0.42$ & $28 \pm 4.44$ & $40.81 \pm 7.01$ & $2.44 \pm 0.33$ & $35 \pm 5.93$ \\
\hline & Significant Dif. & & ns & * & ns & * & ns & ns \\
\hline \multirow[t]{3}{*}{ Girls } & Low-L & 30 & $33.21 \pm 5.98$ & $2.86 \pm 0.48$ & $23.71 \pm 5.79$ & $36.16 \pm 6.26$ & $2.75 \pm 0.42$ & $28.39 \pm 5.37$ \\
\hline & High-L & 44 & $34.32 \pm 5.96$ & $2.53 \pm 0.34$ & $25.96 \pm 4.85$ & $37.91 \pm 6.71$ & $2.45 \pm 0.40$ & $32.26 \pm 6.57$ \\
\hline & Significant Dif. & & ns & $* *$ & ns & ns & $* *$ & * \\
\hline
\end{tabular}

\section{Discussion}

Regarding body composition, no significant differences were found between the participants from medium-high or low socioeconomic backgrounds in any of the variables except height, with participants with a medium-high socioeconomic status being taller. These results are compatible with those of other studies [9,11]. However, in those studies, significant differences were found for almost all variables. These results should take into account the percentage of immigrants in the school with a low socioeconomic level: authors $[19,20]$ have indicated that body composition differs between native and foreign participants, so the percentage of immigrants could lead to falsifying the data. The same analysis was, however, performed differentiating between native and foreign participants and the results remained the same in both cases.

Regarding the force variable, evaluated through the CMJ and ABK vertical jump tests, some authors [21-23] have claimed that there are differences in strength between native and immigrant youth that could explain the differences found in our study. Nevertheless, the same analysis was performed comparing native and foreign participants and the existing disparities remained the same in both cases.

With respect to the first measure, the results obtained on the strength of boys at the beginning of the year are compatible with those found in several other studies [9-11]. However, these authors evaluated general physical condition and strength in particular through long jump, whereas in this study, we evaluated strength through high jump. In a study conducted using young people aged 12.5-18.5 years [11], similar results were found: it seems that differences in strength between participants from different socio-economic backgrounds are found in both primary and secondary education, implying they are maintained over the years. Both in this study and the studies mentioned above, results indicate that participants from a medium-high socioeconomic level would have had better strength values based on both the $\mathrm{CMJ}$ and $\mathrm{ABK}$ tests as participants from the low level: $2.2 \pm 0.49 \mathrm{BW}$ versus $2.59 \pm 0.46 \mathrm{BW}$ with $p=0.005$ and $2.19 \pm 0.46 \mathrm{BW}$ versus $2.45 \pm 0.33 \mathrm{BW}$ with $p<0.05$. In addition, we also found in this study that boys from a medium-high socio-economic background obtained higher peaks of power and height. These results differ from another study [9] which found that boys from a low socio-economic background obtained better levels of physical condition and strength.

Regarding the second measure, these differences were found to be going in the same direction at the end of the year, with boys from medium-high socioeconomic backgrounds scoring the best values. However, the differences went from being significant to not being significant anymore. In addition, in the case of peaks of strength, the situation was reversed, with boys from a low socioeconomic background obtaining in turn the best values. Therefore, these boys would be the ones with highest strength values: this contradicts the results of several research studies [9-11] while agreeing with the results of another [9]. However, these studies were cross-sectional, which could explain why the results were corroborated by one study for one of our measurements and refuted by another.

The changes produced could be explained by participants' level of physical activity, since certain authors $[7,8,24]$ have indicated that jump height was higher in groups that carried out more physical 
activity. Therefore, the evaluation of jump height could prove to be an interesting improvement in future research. The fact that these differences scaled down so much and that boys from a low socioeconomic background had better values in peaks of force may be because these boys were in worse physical shape at the beginning of the school year than boys from medium-high socioeconomic levels, which in turn may be due to the fact that they performed less physical activity in the summer. Following a literature review, other author [25] concluded that during the summer, levels of physical activity were reduced. Perhaps this reduction is accentuated for boys from a low socioeconomic background because of its financial implications. This would demonstrate an absence of social equity and insufficient sustainable development in this specific area. Therefore, we draw our attention again to the importance of evaluating subjects' level of physical activity, differentiating between the school period and the holiday period, since certain authors [26] indicate that socioeconomic status influences performed levels of physical activity. In addition, the level of physical activity is related to other factors such as academic performance [27].

Lastly, regarding the strength of girls at the beginning of the school year, our results coincide with those of other authors [9-11], obtaining greater jump distances for girls from a medium-high socioeconomic level. However, the results obtained by these authors do not reflect real force values, while ours indicate that the peaks of force and power in both groups were similar. Nevertheless, it was found in this case that girls from low socio-economic backgrounds had better values than those from medium-high socioeconomic levels, although these differences were not significant: CMJ $2.55 \pm 0.65 \mathrm{BW}$ compared to $2.42 \pm 0.49 \mathrm{BW}$ and ABK $2.49 \pm 0.63 \mathrm{BW}$ versus $2.33 \pm 0.50 \mathrm{BW}$. However, at the end of the year these differences remained the same and, in addition, they became significant: CMJ values of $2.86 \pm 0.48 \mathrm{BW}$ compared to $2.53 \pm 0.34 \mathrm{BW}$ and $\mathrm{ABK}$ of $2.75 \pm 0.42 \mathrm{BW}$ compared to $2.45 \pm 0.40 \mathrm{BW}$. In both cases, we obtained values of $p<0.005$. In this case, as in the case of boys when performing related sample $t$-tests, participants from a low socio-economic background improved more than the others, and this may be due to the fact that during the school period, the level of physical activity carried out by participants from both groups was more equitable, as it did not involve any financial cost. This would again demonstrate the need for sustainable development in the sports field, guaranteeing social equity in this respect. It would also be useful to prove the value of Physical Education classes in their ability to foster healthy habits, as a means to improve physical condition and as a tool for social inclusion, as pointed out by various authors [28,29].

The strengths of this study include a double measurement to observe the evolution of the variables studied. In addition, the results have been isolated based on variables that could affect the results, such as sex. On the other hand, as limitations, there were other variables that could not be taken into account, such as the level of physical activity. Age could be another study variable to be taken into account in future research, with a larger sample, that could be stratified in the 6 years that make up this educational stage.

\section{Conclusions}

At the beginning of the school year, boys of Primary Education from a medium-high socioeconomic background had better values of lower limb extension explosive strength than boys from a low socio-economic background. They obtained better peaks of strength, power and jump height, both in CMJ and ABK tests. Nevertheless, these differences were reduced at the end of the school year, and became insignificant for most of the variables except for CMJ strength peak and the ABK power peak. In addition, boys from a low socio-economic background in turn, gained the best peaks of force registered in both jumps.

For girls, there seemed to be no differences in the values of explosive force of lower limb extension at the beginning of the school year, since the only significant difference found was is in jump heights. However, at the end of the school year, there were significant differences in the strength peaks of both jumps, with those of girls from a low socioeconomic status being higher.It seems that for all studied 
strength variables, boys and girls from a low socioeconomic status were those who improved the most between the beginning and end of the school year.

Regarding body composition, no significant differences were observed between the medium-high and low socioeconomic background participants in any of the variables, except for body height at the beginning of the year and the body mass of girls at the end of the year. The former being taller, and the latter being heavier.

The results of this study seem to indicate that there is a social difference, in most of the variables studied, depending on the period of the year.

Author Contributions: Amador Jesús Lara Sánchez conceived and designed the experiments; Francisco José López Gallego performed the experiments, analysed the data and wrote the paper; José Antonio Pérez Turpin reagents/materials/analysis tools; Javier Cachón Zagalaz performed the experiments and contributed reagents/materials/analysis tools.

Conflicts of Interest: The authors declare no conflict of interest.

\section{References}

1. López Ricalde, C.D.; López-Hernández, E.S.; Ancona Peniche, I. Desarrollo sustentable o sostenible: Una definición conceptual. Horiz. Sanit. 2005, 4, 28-34. [CrossRef]

2. Benitez-Sillero, J.D.; Perez-Navero, J.L.; Tasset, I.; Guillen-Del Castillo, M.; Gil-Campos, M.; Tunez, I. Cardiorespiratory fitness and oxidative stress: Effect of acute maximal aerobic exercise in children and adolescents. J. Sports Med. Phys. Fit. 2011, 51, 204-210.

3. Ruiz, J.R.; Castro-Pinero, J.; Artero, E.G.; Ortega, F.B.; Sjöström, M.; Suni, J.; Castillo, M.J. Predictive validity of health-related fitness in youth: A systematic review. Br. J. Sports Med. 2009, 43, 909-923. [CrossRef] [PubMed]

4. Ortega, F.B.; Ruiz, J.R.; Castillo, M.J.; Sjöström, M. Physical fitness in childhood and adolescence: A powerful marker of health. Int. J. Obes. 2008, 32, 1-11. [CrossRef] [PubMed]

5. Ramsay, S.E.; Whincup, P.H.; Morris, R.; Lennon, L.; Wannamethee, S.G. Is socioeconomic position related to the prevalence of metabolic syndrome? Influence of social class across the life course in a population-based study of older men. Diabetes Care 2008, 31, 2380-2382. [CrossRef] [PubMed]

6. Gómez-Landero, L.A.; Vernetta, M.; López-Bedoya, J. Análisis comparativo de la capacidad de salto en gimnastas de trampolín españoles. Rev. Int. Cienc. Deporte 2011, 24, 191-202. [CrossRef]

7. Torres-Luque, G.; Carpio, E.; Lara Sánchez, A.; Zagalaz Sánchez, M.L. Niveles de condición física de escolares de educación primaria en relación a su nivel de actividad física y al género. Retos Nuevas Tend. Educ. Fis. Deporte Recreat. 2014, 25, 17-22.

8. López Gallego, F.; Lara Sánchez, A.J.; Espejo Vacas, N.; Cachón Zagalaz, J. Influencia del género. la edad y el nivel de actividad física en la condición física de alumnos de educación primaria. Revisión Bibliográfica. Retos Nuevas Tend. Educ. Fis. Deporte Recreat. 2016, 29, 129-133.

9. Freitas, D.; Maia, J.; Beunen, G.; Claessens, A.; Thomis, M.; Marques, A.; Crespo, M.; Lefevre, J. Socio-economic status, growth, physical activity and fitness: The Madeira Growth Study. Ann. Hum. Biol. 2007, 34, 107-122. [CrossRef] [PubMed]

10. Mutunga, M.; Gallagher, A.M.; Boreham, C.; Watkins, D.C.; Murray, L.J.; Cran, G.; Reilly, J.J. Socioeconomic differences in risk factors for obesity in adolescents in Northern Ireland. Int. J. Pediatr. Obes. 2006, 1, 114-119. [CrossRef] [PubMed]

11. Jiménez-Pavón, D.; Ortega, F.B.; Ruiz, J.; Chillón, P.; Castillo, R.; Artero, E.G.; Martinez-Gómez, D.; Vicente-Rodríguez, G.; Rey-López, J.P.; Gracia, L.A.; et al. Influence of socioeconomic factors on fitness and fatness in Spanish adolescents: The AVENA study. Int. J. Pediatr. Obes. 2010, 5, 467-473. [CrossRef] [PubMed]

12. Cometti, G. La Pliometría; INDE Publicaciones: Barcelona, Spain, 1998.

13. Navarro, I. Los efectos del entrenamiento de fuerza-resistencia en mayores. Rev. Trances 2010, 2, $142-152$.

14. Fleck, S.J. Perceived benefits and concerns of resistance training for children and adolescents. Rev. Kronos 2011, 10, 15-20. 
15. Abián, J.; Alegre, L.M.; Lara, A.J.; Aguado, X. Diferencias de sexo durante la amortiguación de caídas en tests de salto. Arch. Med. Deporte 2006, 23, 441-449.

16. Castillo Díaz, A.; Canalejo Ballester, J.; Martínez Caro, E.; Muñoz Ángel, A.M.; Bermejo Meroño, G.; Garrido Jiménez, J.M.; Armada Ros, E. Estudio Comparativo Sobre la Capacidad de Salto. Flexibilidad y Resistencia Entre Futbolistas y Escolares de 13 años de la Ciudad de Cartagena. 2005. Available online: http:// nuevoarchivo.cartagena.es/archivos/115-2148-DOC_FICHERO/estudio_comparativo.pdf (accessed on 16 January 2018).

17. González Montesinos, J.L.; Díaz Romero, N.; García Rodríguez, L.; Mora Vicente, J.; Castro Piñero, J.; Facio Silva, M. La capacidad de salto e índice de elasticidad en Educación Primaria. Rev. Int. Cienc. Deporte 2007, 7, 359-373.

18. VV.AA. Datosy Cifras del Curso Escolar 2016/17; Ministerio de Educación. Cultura y Deporte: Madrid, Spain, 2016.

19. Fitzgerald, N.; Himmelgree, D.; Damio, G.; Segura-Perez, S.; Peng, Y.; Perez-Escamilla, R. Acculturation, socioeconomic status, obesity and lifestyle factors among low-income Puerto Rican women in Connecticut, U.S., 1998-1999. Pan Am. J. Public Health 2006, 19, 306-313. [CrossRef]

20. Renzaho, A.M.; Gibbons, C.; Swinburn, B.; Jolley, D.; Burns, C. Obesity and undernutrition in sub-Saharan African immigrant and refugee children in Victoria. Australia. Asia Pac. J. Clin. Nutr. 2006, 15, 482-490. [PubMed]

21. Pardo Arquero, V.P.; Jiménez Pavón, D.; Guillén del Castillo, M.; Benítez Sillero, J.D. Actividad física. condición física y adiposidad: Inmigrantes versus escolares españoles/Physical activity, fitness and adiposity: Immigrants versus Spanish scholars. Rev. Int. Cienc. Deporte 2014, 14, 319-338.

22. Treviño, R.P.; Fogt, D.L.; Wyatt, T.J.; Leal-Vasquez, L.; Sosa, E.; Woods, C. Diabetes risk, low fitness and energy insufficiency levels among children from poor families. J. Am. Diet. Assoc. 2008, 108, 1846-1853. [CrossRef] [PubMed]

23. Zahner, L.; Muehlbauer, T.; Schmid, M.; Meyer, U.; Puder, J.J.; Kriemler, S. Association of Sports Club Participation with Fitness and Fatness in Children. Med. Sci. Sports Exerc. 2009, 41, 344-350. [CrossRef] [PubMed]

24. Carrasco Fernández, J.C.; Calahorro Cañada, F.; Lara-Sánchez, A.J.; Torres-Luque, G. Efectos de un Programa de Entrenamiento de Fútbol sobre la Condición Física en Jugadores Jóvenes. Kronos 2014, 13, 1.

25. Baranowski, T.; O'Connor, T.; Johnston, C.; Hughes, S.; Moreno, J.; Chen, T.; Meltzer, L.; Baranowski, J. School year versus summer differences in child weight gain: A narrative review. Child. Obes. 2014, 10, 18-24. [CrossRef] [PubMed]

26. Wei, Y.D.; Xiao, W.; Wen, M.; Wei, R. Walkability, Land Use and Physical Activity. Sustainability 2016, 8, 65. [CrossRef]

27. Batista, M.; Sixto, D.; Honorio, S.; Martins, J. The practice of physical activity related to selfesteem and academical performance in students of basic education. J. Hum. Sport Exerc. 2016, 11, 297-310. [CrossRef]

28. Calzada, J.L.; Cachón, J.; Lara, A.; Zagalaz, M.L. Influencia de la actividad física en la calidad de vida de los niños de 10 y 11 años. J. Sport Health Res. 2016, 8, 231-244.

29. Frutos-de-Miguel, J. El Autoconcepto Físico como herramienta de Inclusión Social en el área de Educación Física. J. Sport Health Res. 2018, 10, 25-42.

(C) 2018 by the authors. Licensee MDPI, Basel, Switzerland. This article is an open access article distributed under the terms and conditions of the Creative Commons Attribution (CC BY) license (http://creativecommons.org/licenses/by/4.0/). 